\title{
A experiência etnográfica: sobre habitar e ser habitado pelo mundo Apyãwa
}

\author{
The ethnographic experience: about to inhabit and be inhabited by the \\ Apyãwa world
}

João Severino Filho*

\begin{abstract}
Resumo
Este texto foi organizado com a função de discutir aspectos metodológicos da pesquisa que desenvolvi em torno do tema Marcadores de Tempos Indígenas, na perspectiva do Programa de Pesquisa Etnomatemática. Nele estão explícitas minhas percepções sobre a etnografia e o processo de construção do meu olhar para a sociedade Apyãwa (minhas escolhas, posicionamentos metodológicos e suas justificativas). Meus pressupostos baseiam-se no entendimento de cultura como uma teia simbólica, tecida na relação entre o ethos e a visão de mundo de um povo que, ao tecê-la, estabelece vínculos, a ela se prende. Produz, socializa e atualiza seus conhecimentos, cuja análise suscita a etnografia, enquanto um modo de descrever e interpretar o fluxo do discurso social dos seus praticantes. O texto etnográfico apresenta-se como um discurso produzido pelo etnógrafo na tarefa de tornar plausíveis realidades de culturas distintas. Praticar etnografia junto ao povo Apyãwa representou a possibilidade de perceber a teia cultural sendo tecida; de participar de um período histórico do conhecimento sendo produzido, atualizado e ensinado como parte intrínseca a sua prática cultural, e de ouvir narrativas que explicam e justificam essa prática. Enfim, foi a possibilidade de contemplar, em toda essa complexidade, as nuances da personalidade, do jeito de interagir com o outro e com o meio em que se vive, que constituem o povo Apyãwa e que o distingue enquanto grupo cultural.
\end{abstract}

Palavras-chave: Etnomatemática. Cultura indígena. Visão de mundo. Ethos. Prática cultural.

\begin{abstract}
This text was organized with the purpose of discussing methodological aspects of research developed around the theme "Indigenous Time Markers", under the view of Ethnomatematics Research Program. In this work, I explained my own perceptions about the ethnography and the construction process of my view about the Apyãwa community. It explains my choices, methodological positions and their justifications as well. My assumptions are based on the understanding of culture as a symbolic web, woven into the relationship between the ethos and the world view of some people (which when woven, establishes links, sticking to it. Produces, socializes and updates their knowledge) whose analysis raises the ethnography, as a way to describe and interpret the flow of social discourse of these culture members. The ethnographic text is presented as a discourse produced by the ethnographer with the task of making plausible the realities of different cultures. To practice ethnography with the Apyãwa people represented the possibility of realizing the cultural web being woven; of participating in a historical period of knowledge being produced, updated and taught as an intrinsic part of their cultural practice and to hear narratives that explain and justify this practice. Ultimately, it was the possibility to contemplate, in all this complexity, nuances of personality, the way they interact with each other and with the environment in which they live, that constitute the Apyãwa people and distinguishes them as a cultural group.
\end{abstract}

Keywords: Ethnomatematics. Indigenous culture. World view. Ethos. Cultural practices.

\footnotetext{
* Doutor em Educação Matemática pelo Programa de Pós-Graduação em Educação Matemática do Instituto de Geociência e Ciências Exatas da Universidade Estadual Paulista (UNESP) Rio Claro. (Bolsista FAPESP), sob orientação do Prof. Dr. Ubiratan D'Ambrosio. Professor da Universidade do Estado de Mato Grosso (UNEMAT), Barra do Bugres, Mato Grosso, Brasil. Endereço para correspondência: Rua da Maravilha, 771 Bairro Cavalhada, 78.200-000, Cáceres, Mato Grosso, Brasil. joaofilho@unemat.br.
} 


\section{Introdução}

O texto A experiência etnográfica: sobre habitar e ser habitado pelo mundo Apyãwa foi organizado com a função de discutir aspectos metodológicos da pesquisa que desenvolvi em torno do tema Marcadores de Tempos Indígenas ${ }^{1}$, na perspectiva do Programa de Pesquisa Etnomatemática (SEVERINO-FILHO, 2015).

Nesse sentido, faço um recorte para tratar especificamente da metodologia utilizada e, devido ao espaço disponível e ao objetivo da publicação a que ele se destina, as discussões sobre o campo, bem como sobre os resultados alcançados, se aterão àquelas essenciais para as reflexões que pretendo apresentar sobre a pesquisa etnográfica em si.

A partir do que denominei A Metáfora da câmera do meu olhar, onde apresento uma ilustração sobre como se deu minha iniciação no campo, intento retratar o contexto em que meu olhar se aproximou e permitiu submeter-se ao olhar dos diferentes personagens da comunidade. Acrescento a esse cenário, a dimensão emocional de minhas percepções iniciais sobre esses personagens, na interação com o grupo social ao qual pertencem. Essas percepções foram determinantes no processo de construção do meu olhar para o fluxo do discurso social Apyãwa. Nesta seção, busco evidenciar minhas escolhas e posicionamentos metodológicos e suas justificativas.

Os Apyãwa (Tapirapé) são um povo Tupi-Guarani que habitam duas Áreas Indígenas situadas na Região do Médio Araguaia, Estado de Mato Grosso. A Área Indígena Tapirapé/Karajá, homologada em 1983, onde coabitam as comunidades Tapirapé e Karajá, localizada na desembocadura do rio Tapirapé, quando deságua no Rio Araguaia, e a Área Indígena Urubu Branco, homologada em 1998. De acordo com informações obtidas pelos Apyãwa, a partir de um levantamento efetuado no final do ano de 2013, a população é de aproximadamente 1000 habitantes.

A Área Indígena Urubu Branco é o território tradicional Apyãwa. O antropólogo Herbert Baldus (1979) faz referências a registros dos bandeirantes e padres que passaram e viveram por ali no início do século XVII, em que constam informações sobre a presença desse povo em toda a região circunvizinha. Entretanto, na década de 1960, o território foi ocupado por fazendas de agropecuária.

Na década de 1990, os Apyãwa conseguiram a liberação oficial das duas Terras Indígenas e grande parte da população retorna ao Território Urubu Branco, onde atualmente

\footnotetext{
1 Sobre os Marcadores de Tempos Indígenas, veja Severino-Filho (2013). Acesso disponível em: http://sbem.esquiro.kinghost.net/anais/XIENEM/pdf/3538_1961_ID.pdf.
} 
estão distribuídos em sete aldeias: Tapi'itãwa, Akara'ytãwa, Myryxitãwa, Tapiparanytãwa, Towajaatãwa, Wiriaotãwa e Inatãotãwa.

Com a retomada do antigo Território, o povo passou a se autodenominar Povo Apyãwa, nome que havia caído em desuso depois do contato com a sociedade não indígena, a qual lhes atribuiu o nome Tapirapé. O termo Apyãwa, do tupi, pode ser traduzido da seguinte forma: o morfema-ãwa (gente, pessoa); apyaba (varão, homem, macho, gentio). Como forma de respeito à luta desse povo pela sua autodenominação, opto por referir-me a eles, predominantemente, pelo nome Apyãwa.

Minha presença como pesquisador que, entre outras coisas, me possibilitaram realizar as observações e conviver com a rotina das comunidades, ocorreu nos anos de 2013 e 2014, principalmente, na Aldeia Tapi'itãwa, a maior e mais antiga aldeia do território habitado pelo povo Apyãwa.

A realização da pesquisa de que trata este artigo teve como objetivo central constituir um conjunto de estudos e reflexões sobre os conhecimentos de povos indígenas e suas epistemologias, percebidos pela descrição de significados dos fenômenos marcadores de tempos, identificados e observados pelo povo Apyãwa, a partir das explicações presentes nas narrativas sobre as cosmologias e ritos e das relações que estabelecem com as atividades cotidianas.

A fase da pesquisa dedicada ao campo teve duração aproximada de 12 meses, sendo composta de momentos de imersão, intercalados por momentos de distanciamento do campo. As incursões e imersões ao campo tiveram duração média de 15 dias, sofriam variações de acordo com as atividades e rituais realizados pela comunidade Apyãwa, bem como com o cronograma de reuniões mensais do Grupo de Estudos e Pesquisa em Etnomatemática GEPEtno $^{2}$ e encontros com o professor Ubiratan D'Ambrosio, orientador desta pesquisa.

A alternância entre os momentos de imersão e de distanciamento da realidade pesquisada, metodologicamente, teve a função de, além de permitir-me verbalizar as observações e reflexões conseguidas e ouvir questionamentos sobre as mesmas, proporcionar diferentes olhares e novas indagações sobre realidade estudada.

\section{Situar-me Geertziano na realidade do Povo Apyãwa}

\footnotetext{
${ }^{2}$ Grupo de Estudo e Pesquisa em Etnomatemática - composto por docentes, alunos e ex-alunos de mestrado e doutorado do Programa de Pós-graduação em Educação Matemática da UNESP/Rio Claro - é coordenado pelo Professor Ubiratan D’Ambrosio.
} 
As observações e estudos no campo tiveram início no mês de março de 2013. Ao chegar à aldeia, no dia 02 de março, observei um grupo de aproximadamente 30 homens, jovens e adultos, formando um círculo no terreiro da Takãra (Casa dos Homens). Tratava-se de uma dança ritualística chamada Kawãwoo.

Os mais jovens se posicionam no final da fila circular. Por último, sem uma organização definida (ou pelo menos alguma que eu pudesse identificar) e de forma brincalhona, vinham algumas crianças, que repetiam os movimentos dos adultos, abandonavam o círculo e retornavam a ele, aleatoriamente, sem despertar nenhum incômodo aos mais velhos ou receberem algum tipo de repreensão, mesmo quando estes eram obrigados a mudar a trajetória do círculo em função dos pequenos.

Antes de me dirigir ao Terreiro da Takãra (Takawytera), havia passado pela residência das irmãs missionárias Genoveva e Odila ${ }^{3}$, as quais contribuíram para o esclarecimento de algumas questões quanto ao comportamento de visitante e me deram segurança de que minha presença seria bem recebida nas proximidades do ritual.

Sentei-me em um pedaço de madeira à sombra da Takãra e ali permaneci até que encerrassem o ritual. Percebi que se aproximava do fim quando o líder se separou do círculo e dirigiu-se para uma das portas de entrada da Takãra, gesto que foi seguido pelos demais. No interior da Takãra, ainda permaneceram cantando por alguns minutos e, para finalizar o ritual, emitiram gritos alegres e, aparentemente, comemorativos pela atividade realizada.

Em seguida, Xario'i Carlos (Cacique da Aldeia Tapi 'itãwa), que fazia parte do grupo, saiu da Takãra e sentou-se ao meu lado. Contei-lhe sobre o tema de minha pesquisa e sobre a minha escolha por desenvolvê-la juntamente com eles. Disse a ele que o principal motivo da minha visita, naquele momento, seria para solicitar seu consentimento e de sua comunidade.

Permanecemos conversando um pouco mais sobre o tema de minha pesquisa, entreguei-lhe o Termo de Anuência Prévia. Após sua leitura, comentou que aquele momento era muito propício, já que havia lideranças das diferentes aldeias participando do ritual e que poderiam ser consultadas.

Antes que o grupo se dispersasse, ele se dirigiu até o meio do Takawytera (terreiro da Takãra) e os convocou para conversarem sobre minha solicitação. Avaliei que deveria seguilo e permaneci ao seu lado, esperando, apreensivo, pelo que aconteceria naquela reunião.

O grupo se formou novamente e recebeu a adesão de outras pessoas da aldeia que não participavam do ritual, mas tiveram a curiosidade de saber sobre o que estariam discutindo

\footnotetext{
${ }^{3}$ Missionárias da Fraternidade Irmãzinhas de Jesus, religiosas católicas que convivem com os Apyãwa desde 1952.
} 
com o visitante. Xario'i Carlos iniciou a conversa, sobre a qual eu entendia apenas que o assunto era a minha solicitação.

Porém, os detalhes e o conteúdo daquela conversa, a mim eram estranhos, pois falavam na língua Apyãwa, que não era do meu domínio. Acompanhava a entonação de Xario'i Carlos e seus gestos, supondo que ora ele explicava aos demais sobre detalhes da pesquisa, quando apontava para o Termo de Anuência em suas mãos, ora parecia falar a meu respeito, principalmente quando apontava para mim ou tocava no meu ombro. Ao finalizar sua fala, Xario'i Carlos foi questionado por alguns deles, ainda na língua Apyãwa, aos quais ele respondeu sem a necessidade de me consultar.

Terminadas as arguições ao Cacique Xario'i Carlos, eles passaram a me perguntar, em português, sobre diferentes assuntos relacionados à Unesp e às minhas viagens aéreas. Apenas uma ou duas questões foram levantadas sobre minha pesquisa.

Antes de o círculo se desfazer, dois anciãos proferiram um discurso, o qual, apesar de ser na língua Apyãwa, pelos gestos e olhares que me dirigiam, entendi que as falas seriam para todo o grupo, incluindo a mim. Logo em seguida, o Cacique Xario'i Carlos traduziu o teor das falas, comunicando-me que eles diziam estar muito felizes por eu ter escolhido realizar essa fase dos meus estudos com eles e que me receberiam com muita satisfação, se colocando à disposição para tudo que eu necessitasse enquanto novo membro da comunidade.

\subsection{Em um país chamado Tapi’itãwa}

A realização de um trabalho etnográfico implica no cumprimento de algumas etapas, que se apresentam como necessárias em um período muito anterior às incursões no campo para as primeiras observações. Dentre elas, o conhecimento mínimo da realidade onde serão realizados os estudos e o esclarecimento e consentimento prévios dos sujeitos envolvidos, quanto às intenções do pesquisador, têm relevância inquestionável. Assim, mesmo prevendo contar como certa a aprovação da comunidade Apyãwa, no momento em que me preparava para realizar a pesquisa, optei por uma inversão no protocolo de encaminhamento do processo de solicitação da autorização para ingresso e permanência em terras indígenas. Procedimento utilizado por Silva (2013).

Por esse motivo, me esforcei no sentido de providenciar, primeiramente, a comunicação, e obter a anuência das lideranças da comunidade, a qual incorporei ao processo constituído por todos os documentos exigidos pela legislação e encaminhados à Fundação 
Nacional do Índio (FUNAI). Avaliei que esta seria uma das formas de respeitar a autonomia e a opinião do povo com os quais pretendia realizar o trabalho de campo.

No campo, cada perspectiva teórica suscita um conjunto de procedimentos metodológicos e técnicas de estudos, os quais, creio, devem ser considerados pelo pesquisador. Entretanto, concordo com Geertz (2008, p. 04) quando afirma que o que define e dá identidade ao trabalho etnográfico não são as técnicas e métodos a serem seguidos e explicitados. Não é a prática do pesquisador, mas, sim, "o tipo de esforço intelectual que ela representa" em suas teorizações, à luz das percepções conseguidas com a realidade na qual ele imerge, que vai caracterizar a sua pesquisa e dar o tom para as esperadas produções futuras.

Entendo que, nas opções por cada procedimento a ser seguido durante o trabalho no campo, em cada ação programada já se torna explícito o olhar do pesquisador sobre a realidade em estudo. Assim, ao iniciar as incursões ao campo, esperamos estar munidos de todas as ferramentas, instrumentais e teóricas, para executar as tarefas de forma adequada e tomar as decisões necessárias diante de cada situação.

Contudo, nos primeiros dias de convívio no campo já foi possível concluir que, se realmente queria fazer etnografia, não haveria como manter sob controle as experiências pelas quais passaria. Concluí que, para praticá-la, a principal ferramenta que eu deveria portar seria a capacidade de situar-me entre eles (GEERTZ, 2008), de perceber a vida fluir e fazer parte desse fluxo.

Preparei-me para o trabalho de campo, para estudar na aldeia, não para estudar $a$ aldeia. Meu principal objetivo seria conversar com eles, e não copiá-los ou me tornar um deles. Para situar-me entre eles na perspectiva proposta por Geertz (2008), deveria compreendê-los, não apenas, compreender o que falavam entre si ou comigo.

Considerando o tempo disponível para realização dos trabalhos de campo, organizeime para a incursão e permanência na aldeia a partir do que poderia ser explicado por uma analogia com a mudança para um pequeno país chamado Tapi’itãwa e todos os cuidados, considerações, procedimentos e implicações que deveriam ser levados em conta para situarme como novo habitante desse país.

Nesse sentido, para não me tornar o novo habitante inconveniente, me atentei para os cuidados possíveis, na tentativa de amenizar os constrangimentos ou transtornos causados, inevitavelmente, pela a minha presença. Busquei evitar o excesso de abordagens e de inquéritos, o uso inconveniente, em alguns momentos, da máquina fotográfica e do gravador de voz. 
A comunidade Apyãwa sabe o motivo da minha presença na aldeia. Muitos pesquisadores já passaram por lá e isso, acredito, fez com que eles construíssem um perfil geral sobre o interesse e comportamento desses visitantes. Procurei fugir, cuidadosamente, desse estereótipo, evitando demonstrar interesse exagerado por qualquer fenômeno, sem também desdenhar. Evitei fazer questionamentos e, quando os fazia, sempre ocorria no contexto de uma conversa em que eles espontaneamente estavam explicando-me sobre determinado assunto.

Minha presença os instigava a conversar sobre si. Aqueles que tiveram mais contato com os outros pesquisadores, inclusive, provavelmente se indagavam sobre o meu método. Alguns me abordaram, logo de início, para saber se eu estaria acompanhando algum grupo específico, uma família, se havia uma pessoa me fornecendo informações, um entrevistado ou algo que indicasse que estivesse pesquisando sobre eles.

\subsection{A metáfora da Câmera do meu olhar}

Apesar das considerações citadas anteriormente, ao iniciar as observações deparei-me com o inevitável estranhamento por estar diante do outro. Nos primeiros momentos, caminhar pelo pátio da aldeia, me aproximar de grupos familiares em seus quintais, ou dos lugares onde acontecia alguma atividade ritualística, causava-me sensações de estranhamento, de desconforto e insegurança, por não conseguir prever o que ocorreria. Minha presença, meu olhar, minhas intenções de pesquisador causavam-me apreensão, por também imaginar o constrangimento que poderia estar provocando às pessoas, quanto à intenção de minha abordagem ou simples aproximação.

O que melhor poderia ilustrar minha iniciação no campo é o que denominei a Metáfora da câmera do meu olhar. Uma ferramenta guiando o meu olhar, composta por tudo que reuni, enquanto preparação, para estar ali, incluindo-se estudos anteriores sobre o tema e as questões levantadas no projeto de pesquisa.

Entretanto, apesar de todo o aparato construído, ao me deparar com a realidade do campo, não conseguia decidir para onde deveria apontar a câmera. Inclusive, a sensação inicial era de que, toda vez que eu a posicionava em determinada direção, as lentes se tornavam translúcidas e a imagem capturada, distorcida pelo jogo de lentes da câmera, em nada se assemelhava com a complexa realidade a qual tentava apreender.

Não percebi o exato instante em que abri mão de manipular ou de comandar os registros produzidos pela câmera do meu olhar. Apenas observei, a partir de determinado 
momento, que ela passava pelas mãos de cada membro da comunidade Apyãwa. Em alguns momentos, os homens anciãos (Maryke'yri), no Takawytera (terreiro da Takãra) a direcionavam para as tradições do povo, para as histórias dos antepassados, para o mundo espiritual Apyãwa e acontecimentos que testemunhavam o grande poder dos antigos pajés.

As imagens produzidas pelos Maryke'yri durante o dia, sentados em um banco de madeira ou deitados em suas redes nos quintais, acompanhavam cada movimento, cada atividade ou fala dos membros de seu grupo familiar. São chefes dos grupos familiares e seu poder de liderança diante da comunidade, em parte, está relacionado ao tamanho do grupo e qualidade de seus membros.

Em determinadas noites, nas mãos dos homens adultos (Maryke'yra), importantes personagens e lideranças Apyãwa, a imagem se ampliava, ultrapassava os limites do território, alcançava povos vizinhos e os acontecimentos políticos, econômicos e esportivos nacionais. Em outras, focava os agrupamentos dos jovens, observando suas atividades, seus interesses. São olhares de preocupação com o futuro do povo. Tentavam intensificar a presença de jovens no Takawytera (terreiro da Takãra), onde recebem os ensinamentos dos velhos, aprendem sobre os rituais, sobre o passado, as dificuldades e os perigos do presente.

Durante o dia, as imagens produzidas pelos Maryke'yra focam suas atividades produtivas nas roças, na fabricação de farinha nos quintais, nas pescarias ou caçadas individuais para provimento de alimentos ao grupo familiar a que pertencem ou em atividades de reforma e manutenção de suas residências.

A câmera nas mãos das mulheres adultas (wajwĩ) mostrava a perspicácia. Eram imagens obtidas de um ponto mais distante. Geralmente, dos quintais ou dos pequenos bancos de madeiras à frente das residências, de onde se tem todo o panorama da aldeia e, também, de onde se ouve praticamente tudo que é conversado no Takawytera (terreiro da Takãra). Ora o foco estava nas atividades dos homens, e na parte dos rituais que a elas cabia. Ora, a atenção estava nos filhos, netos e em todas as atividades dos grupos familiares se alimentando coletivamente ou apenas reunidos, sorrindo das histórias contadas.

Quando a câmera estava com os jovens, tanto rapazes quanto moças (Awa'yão'i e koxamoko'i'i), as imagens compunham-se de timidez e inquietação. As cenas eram captadas a curta distância e focavam, quase sempre, suas próprias atividades, seus agrupamentos que se isolavam dos demais, onde as conversas, geralmente, eram em baixo tom, contudo, com muitas risadas. Às vezes, notava-se um distanciamento do foco, buscando o infinito, o futuro, apontava para os adultos e anciãos, buscando o sentido de pertencer àquela cultura. 
Finalmente, quando a câmera do meu olhar estava sob os cuidados dos pequenos rapazinhos e meninas (Konomi/namĩ e Kotatãi/atãi), as cenas eram de ousadia, de liberdade, de agilidade em ocupar todos os lugares da aldeia, brincando livremente pelos quintais, riachos e pomares do entorno. Os rapazinhos, com seus estilingues e flechas, percorriam distâncias maiores. Conduziam a câmera por lugares imprevisíveis, entravam e saíam da Takãra sem a menor reverência, quando havia rituais sendo executados. As meninas, também livres, contudo, produziam imagens da câmera na maior parte do tempo no entorno de suas residências. A elas é atribuída a função de cuidar dos bebês (Pityga) e dos rapazinhos e meninas de sua própria fase, recém-saídos da fase de lactação.

O medo inicial em ver minha ferramenta de trabalho passar por cada mão e cada olhar aos poucos foi se dissipando e se convertendo em expectativas. Percebi que não se tratava de desconfiança quanto à capacidade de manipularem o instrumento, mas, sim, do entendimento sobre a fragilidade que ele tinha.

Paulatinamente, passei a observar com naturalidade as diferenças no tempo, no modo e no estilo de cada grupo ao manipular e focar a câmera. À medida que a câmera do meu olhar mudava seu enfoque, os grupos iam descartando seus acessórios e mostrando-me o quanto eram desnecessários a partir dali. Chegaram ao ponto de descartar partes consideráveis da própria câmera, acrescentando outros, os quais nem imaginava existir na aldeia. E, para o meu reconforto, permitiram-me entender como olhar por aquela nova câmera.

Com o passar dos dias, percebi que uma imagem se repetia em cada grupo. Focada diferentemente, dependendo das características desse grupo, ela se modificava. Inicialmente, revelou-se distorcida e obscurecida, contudo, à medida que era reproduzida, essa imagem se tornava mais nítida e familiar. Era o próprio pesquisador sendo filmado pela câmera do seu olhar. A visão de si mesmo e do quanto seu entendimento sobre o mundo se transformava. Era a descoberta de si mesmo a partir do olhar para o outro. A percepção de que eu estava pronto para ler esse conjunto de textos chamado cultura que, como os antropólogos, tentarei "ler por sobre os ombros daqueles a quem eles pertencem" (GEERTZ, 2008, p. 212).

\subsection{0 terreiro da Takãra (Takawytera)}

A Takãra, localizada no centro do pátio da aldeia (Figura 1), é a casa do porcão. Sua construção foi ensinada ao povo Apyãwa pelos seus antigos pajés. De acordo com Wario (Xywaeri José Pio), em uma de suas viagens pelo mundo espiritual, o pajé se encontrou com o 
espírito do porcão que o ensinou como construí-la, como também suas divisões e as regras de sua utilização pelos homens em diferentes fases da vida.

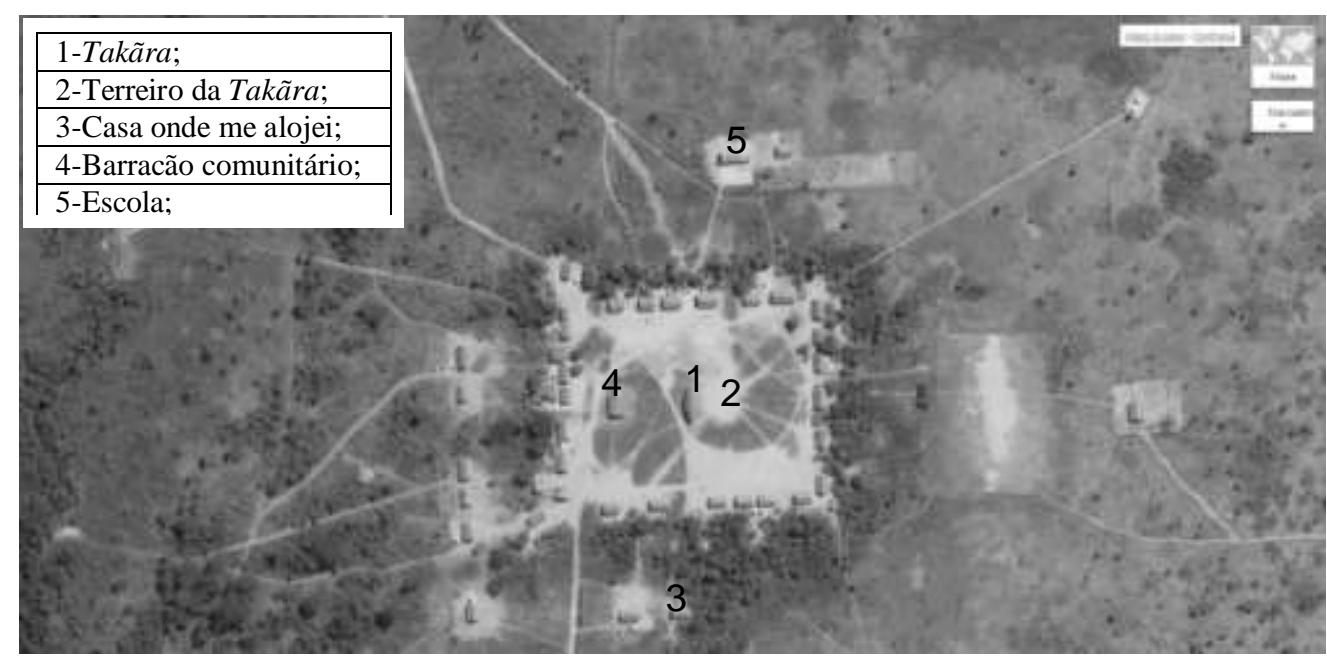

Figura 1 - Aldeia Tapi'itãwa no ano de 2004.

Fonte: Imagem do Google Maps de 03/02/14.

O Povo Apyãwa se organiza socialmente dividido em duas metades (Araxã e wiraxiga), denominadas por eles de Wyrã (aves). Essas metades são compostas de três subgrupos aos quais pertencem os homens e seus familiares, de acordo com a fase de vida em que se encontram (Quadro 1).

No interior da Takãra, cada grupo e subgrupo ocupam lugares específicos. A Metade Araxã , formada pelos grupos Warakorã (jovens entre $2^{\mathrm{a}}$ e $5^{\mathrm{a}}$ fases), Araxã (homens adultos entre $5^{\mathrm{a}}$ e $7^{\mathrm{a}}$ fases) e Tarawe (homens acima da $7^{\mathrm{a}}$ fase - anciãos) ocupa o lado norte da Takãra. A Metade Wyraxiga, formada pelos grupos Wyraxiga (jovens entre $2^{\mathrm{a}}$ e $5^{\mathrm{a}}$ fases), Wiraxigio (homens adultos entre $5^{\mathrm{a}}$ e $7^{\mathrm{a}}$ fases) e Wiraxigoo (homens acima da $7^{\mathrm{a}}$ fase anciãos) ocupa o lado sul da Takãra. Cada subgrupo tem funções determinadas nos rituais.

\begin{tabular}{|c|c|c|c|c|c|}
\hline \multicolumn{6}{|c|}{ As fases de vida do Povo Apyãwa ${ }^{4}$} \\
\hline \multicolumn{3}{|c|}{ Masculino } & \multicolumn{3}{|c|}{ Feminino } \\
\hline & Fase & Características & & Fase & Características \\
\hline $1^{\mathrm{a}}$ & Pityga/xikõj'i & Nascimento ao desmame & $1^{\mathrm{a}}$ & Pityga/mireri & Nascimento ao desmame \\
\hline $2^{a}$ & Konomi/namĩ & Menino & $2^{a}$ & Kotatãi/atãi & Menina \\
\hline $3^{\mathrm{a}}$ & Xyre'i'i & $\begin{array}{l}\text { Rapazinho em pré-fase de } \\
\text { passagem para a vida adulta }\end{array}$ & $3^{a}$ & koxamoko'i'i & $\begin{array}{l}\text { Mocinha. Corpo apresenta } \\
\text { amadurecimento (seios). }\end{array}$ \\
\hline $4^{\mathrm{a}}$ & Awa'yão'i & $\begin{array}{l}\text { Rapazinho em fase de } \\
\text { passagem. Corte de cabelo. }\end{array}$ & $4^{\mathrm{a}}$ & $\begin{array}{l}\text { Koxamoko } \\
\text { xemany'arere }\end{array}$ & $\begin{array}{l}\text { Após passar pela primeira } \\
\text { menstruação. }\end{array}$ \\
\hline $5^{\mathrm{a}}$ & $\begin{array}{l}\text { Awa'yão } \\
\text { Xema'âwi }\end{array}$ & $\begin{array}{l}\text { Homem jovem, após passar pelo } \\
\text { Marakayja (festa do rapaz). }\end{array}$ & $5^{\mathrm{a}}$ & Koxỹxewete & $\begin{array}{l}\text { Mulher adulta. Casada, } \\
\text { com ou sem filhos. }\end{array}$ \\
\hline $6^{\mathrm{a}}$ & Akamã'e xewete & $\begin{array}{l}\text { Homem adulto. Possui família, } \\
\text { filhos ou não. }\end{array}$ & $6^{\mathrm{a}}$ & wajwĩ & $\begin{array}{l}\text { Mulher adulta. Possui } \\
\text { netos. Prepara-se para a } \\
\text { fase de anciã. }\end{array}$ \\
\hline
\end{tabular}

\footnotetext{
${ }^{4}$ Informações produzidas durante uma oficina de atividades do Projeto de Extensão do qual faço parte, intitulado "Formação continuada de professores Tapirapé: produção de saberes e práticas e material de apoio didático/pedagógico no contexto da escola" - UNEMAT/PROEC/PROEG/Diretoria de Gestão de Educação Indígena. Setembro de 2014.
} 


\begin{tabular}{|l|l|l|l|l|l|}
\hline $7^{\mathrm{a}}$ & Maryke'yra & $\begin{array}{l}\text { Homem adulto. Tem netos. } \\
\text { Prepara-se para a fase de ancião. }\end{array}$ & $7^{\mathrm{a}}$ & wajwĩ' $i$ & Mulher idosa. Anciã \\
\hline $8^{\mathrm{a}}$ & Maryke'yri & Homem idoso. Ancião & \multicolumn{2}{|l}{} \\
\hline
\end{tabular}

Quadro 1 - Descrição das fases de vida do povo Apyãwa.

Fonte: O Autor (setembro/2014).

Os grupos das duas metades não se rivalizam. Contudo, competem entre si na obtenção da maior quantidade de caça e pesca para serem consumidos coletivamente nos rituais.

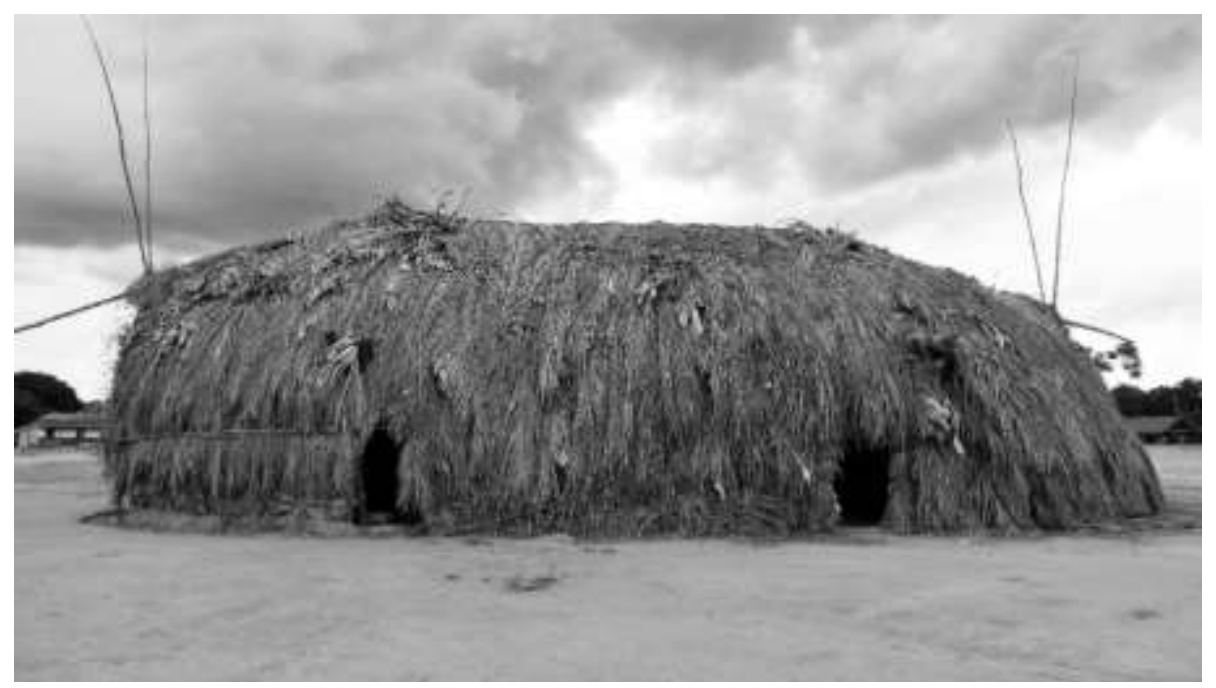

Figura 2 - A nova Takãra. Construída entre dez./13 e jan./14.

Fonte: O Autor (fevereiro/2014).

É uma responsabilidade muito grande para a comunidade local de cada aldeia, a manutenção da Takãra. Se ela existe, todas as atividades ritualísticas deverão existir continuamente. A população deve ser numerosa, suficientemente, para manter as atividades. Isso faz com que, nas aldeias menores, não tenham a Takãra. Então, os habitantes das outras aldeias se deslocam para Tapi'itãwa e ali permanecem durante as atividades mais importantes dos rituais.

O Terreiro da Takãra foi um lugar decisivo para minha inserção na sociedade Apyãwa e aproximação com os anciãos e demais lideranças, para vivenciar momentos em que se manifesta o estilo de vida do povo e, evidentemente, gozar do agradável ambiente criado pelo modo de interação, sempre amigável e atencioso, daquelas pessoas.

É o centro de todas as discussões e decisões relativas à vida coletiva do povo. Lá, além de desenvolverem quase totalidade das atividades relacionadas aos rituais, os homens se reúnem todas as noites para conversarem, socializarem assuntos emergenciais, decidirem sobre atividades coletivas ou mesmo para ficarem em silêncio, contemplando o céu e o ambiente como um todo, até que decidam (individualmente) se recolher para as residências. 
Todo viajante, indígena ou mayra (não indígena), em visita à aldeia com algum assunto de interesse coletivo a ser tratado, ou simplesmente com histórias para contar, recebe o convite do cacique para participar da roda no terreiro da Takãra, onde o assunto será socializado com todos os presentes. No terreiro, todos os discursos proferidos por eles estarão na língua Apyãwa e, caso seja necessário, traduzidos aos visitantes por um voluntário.

Somente os homens participam das conversas no terreiro da Takãra. Contudo, apesar de as falas serem sempre num tom moderado, as mulheres, geralmente, acompanham todo o desenrolar dos assuntos, sentadas em bancos nas portas de suas casas.

Presenciei momentos em que, ao discutirem temas bastante polêmicos e relevantes para a comunidade, as mulheres abandonavam os pátios de suas casas e se aproximavam do terreiro da Takãra. Tais assuntos nunca são concluídos em uma única noite. Os homens levam as diferentes ponderações e posicionamentos para suas casas, discutem com as esposas e demais membros dos núcleos familiares. Na noite posterior poderão ter mais segurança para se posicionar e avançar nas conclusões (que não necessariamente serão finalizadas ali).

Eles sempre conversam entre si utilizando a língua Apyãwa. O uso do português se restringia a momentos em que falavam comigo. Entretanto, a falta de domínio da língua Apyãwa não representava uma barreira de comunicação entre nós. Inclusive, me propiciou leituras dos gestos, das entonações de voz, da organização cotidiana das famílias e da comunidade, da valorização de determinados assuntos, dos comportamentos dos casais entre si e no cuidado com os filhos.

\subsection{A aldeia e as moradias Apyãwa}

As aldeias Apyãwa, no decorrer do tempo, passaram por transformações significativas, tanto na arquitetura das residências quanto no modo como elas se distribuem no espaço. No passado, as residências eram construídas com folhas de palmeiras mescladas com folhas de bananeira brava, como coberturas de uma estrutura de madeiras trançadas em arco que se prolongavam até o chão. Mesmos materiais e formato que constroem a Takãra até os dias de hoje. A disposição das casas formava um grande círculo que delimitava o pátio.

Nos dias atuais, as residências possuem paredes de adobe (blocos de argila) e cobertura de palhas trançadas (Figura 3), conforme aprenderam no contato com os pequenos agricultores não indígenas. Aos poucos, os adobes vão sendo substituídos por tijolos furados adquiridos na cidade. 
As residências, atualmente, estão dispostas em linhas retas, fazendo com que o pátio da aldeia tenha o formato retangular (Figura 1, p. 854). Em todos os quintais há árvores frutíferas com predomínio de grandes mangueiras, verdadeiros pomares de murici e, pelo menos um pé de cuité, do qual coletam o fruto de mesmo nome, usado para confeccionar cuias de diferentes tamanhos para utilização como utensílios domésticos e maracás para os rituais.

Não há cercas limitando os quintais, nem restrições sociais para transitar por entre eles. As pessoas caminham livremente por eles para acessarem as casas dos alinhamentos mais periféricos.

Passaram-se pelo menos seis meses antes que eu adentrasse pela primeira vez em uma residência Apyãwa. Primeiramente, por não ter sido convidado. Depois, acredito que pelo motivo de não ser um local de convívio social, para onde os anfitriões conduzem suas visitas e lhes oferecem assentos.

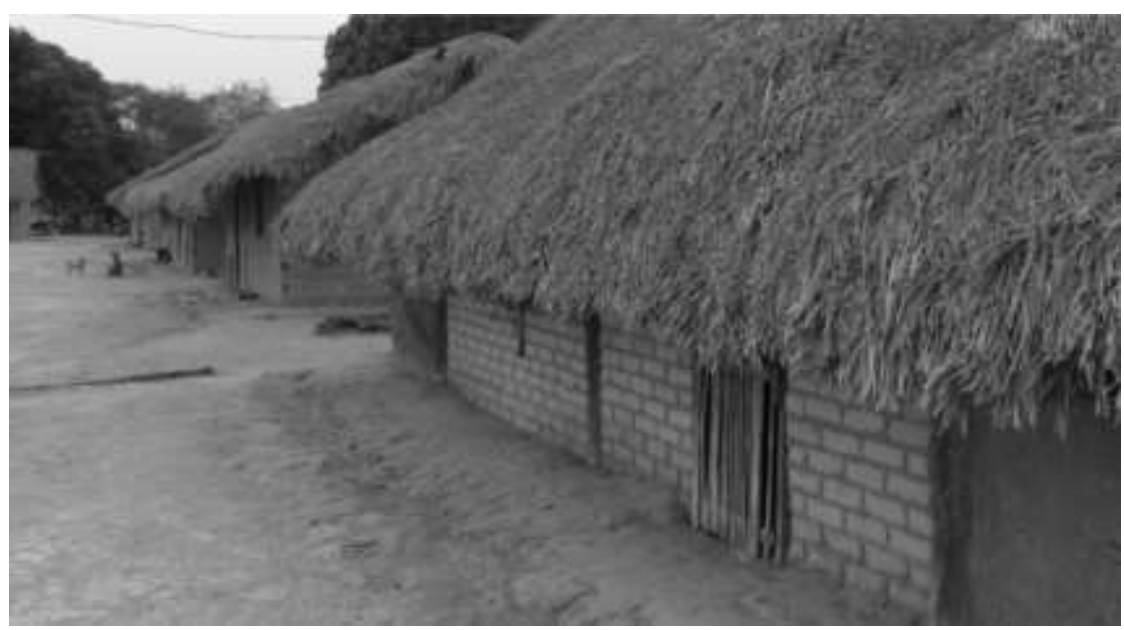

Figura 3 - Residências da Aldeia Tapi'itãwa. Fonte: O autor (outubro/2013).

As residências, geralmente, possuem no máximo uma divisão. Os cômodos são repletos de redes e não há móveis. As janelas são pequenas e em número reduzido. Observei uma grande quantidade de residências que possuíam apenas uma porta de acesso. A chegada da energia elétrica na aldeia, provavelmente, modificou o perfil das moradias e de seu uso. Algumas já possuem televisores e alguns eletrodomésticos.

Minhas visitas a determinados locais se davam, principalmente, no período da tarde, quando os grupos familiares se reúnem nos quintais, às sombras das mangueiras. São momentos de descontração. Estão sempre conversando animadamente, alguns realizam atividades de tecelagem, confecção de ferramentas de trabalho ou de caça e pesca. 


\subsection{Os alimentos tradicionais Apyãwa}

Os Apyãwa praticam a agricultura de pequeno porte, sendo o trabalho na roça destinado aos homens. Eles são conhecidos como competentes agricultores. Suas roças podem ser familiares, individuais e comunitárias (essas últimas são destinadas ao cultivo de alimentos específicos para os rituais).

As roças que visitei - mesmo as comunitárias - possuíam, no máximo, quatro hectares de área plantada. As atividades são manuais, desde a derrubada (que ainda é realizada com machados). Nelas há cultivos de milho (para consumo verde ou maduro; ou, como um dos ingredientes do cauim); de mandioca (para fabricação de farinha de puba, polvilho e cauim); de amendoim (consumido cru ou torrado, na mistura do cauim); de inhame (que consomem cozidos); de banana comprida (utilizada nos rituais, acompanha a carne de porcão) e de melancia.

É comum as famílias plantarem em seus quintais a batata doce, o inhame, o cará, pomares de murici e árvores de pequi e feijões. Geralmente, nos quintais são cultivadas as sementes obtidas por eventuais intercâmbios com outros povos. Ali, eles podem observar o desenvolvimento das plantas (até então desconhecidas), desde a germinação. Quando me mostram seus quintais, cada cultivo tem sua origem (fazem referência ao contexto em que as sementes foram obtidas: época, lugar, pessoas, aprendizagens) e sua história de adaptação ao clima e solo do quintal.

A proteína animal é obtida no consumo da carne de peixes e diferentes animais silvestres (porcão, macaco, veados, aves). Tanto o peixe quanto as carnes dos animais silvestres são consumidos cozidos ou assados (nunca fritos), acompanhados de farinha de puba. Com a intensificação do contato com a sociedade envolvente (mayra), vários produtos alimentícios industrializados (açúcar, sal, bolachas, macarrão, refrigerante e condimentos em geral), como também aqueles produzidos na região, como o arroz, carne bovina e de aves foram inserindo-se, gradativamente, em sua dieta alimentar.

\section{0 conceito de cultura implícito na etnografia}

As discussões sobre o tipo de abordagem metodológica adotada na pesquisa com o povo indígena Apyãwa colocaram-me, logo de início, a necessidade de estabelecer a definição de cultura que identifico como mais próxima das ideias que compõem o Programa Etnomatemática (D’AMBROSIO, 1990, 2002 e 2005), cujas pesquisas buscam interpretar a 
arte ou a técnica de explicar, conhecer e entender nos diversos contextos socioculturais (D’AMBROSIO, 2005).

Apoiamo-nos na definição de Geertz (2008, p. 04), que a concebe como essencialmente semiótica. Acreditando, como Max Weber, que "o homem é um animal amarrado a teias de significados que ele mesmo teceu", Geertz define cultura como sendo essas teias. Assim, pesquisas sobre aspectos de distintos grupos culturais serão realizadas a partir de uma ciência interpretativa, na busca de significados que possam ser atribuídos com plausibilidade, e não como um experimento pelo qual se pretende definir leis gerais.

Como sistemas entrelaçados de signos interpretáveis (o que eu chamaria símbolos, ignorando as utilizações provinciais), a cultura não é um poder, algo ao qual podem ser atribuídos casualmente os acontecimentos sociais, os comportamentos, as instituições ou os processos; ela é um contexto, algo dentro do qual eles podem ser descritos de forma inteligível - isto é, descritos com densidade. (GEERTZ, 2008, p. $10)$.

A cultura, como uma teia simbólica, é necessariamente tecida contínua e coletivamente. E, no processo histórico da dinâmica cultural, os indivíduos reforçam vínculos com sua comunidade, reproduzem e recriam modos de tecer, rompem com alguns nós enquanto tecem outros, criam e recriam explicações para os emaranhados de desenhos resultantes na teia.

Esses emaranhados de desenhos e nós são significados individualmente e na coletividade de um grupo cultural, ao viver suas vidas. São sistemas de símbolos através dos quais os elementos constituintes de uma cultura são elaborados, comunicados, impostos, compartilhados, modificados e reproduzidos.

Enquanto estilo de vida e entendimento sobre o mundo, a cultura é um documento no qual se inscreve a atuação do povo que a pratica. "É portanto pública" (GEERTZ, 2008, p. 08). Desse modo, uma análise cultural deverá, a todo o momento, questionar com a mesma dedicação, o que está sendo transmitido nessa atuação e qual a importância atribuída, tanto aos aparentemente insignificantes cenários, às sombras dos quintais dos grupos familiares, quanto à exuberância e complexidade dos rituais no Terreiro da Takãra.

\subsection{Um possível diálogo entre dois mundos}

Intercalar o período dedicado à pesquisa etnográfica entre as imersões na realidade da aldeia e da academia, participando de discussões nos diferentes espaços desses dois mundos nas noites calmas do Terreiro da Takãra, nas caminhadas pela pista do Campus da Unesp de Rio Claro e, inclusive nos momentos de confraternização com os alunos e professores do 
Programa de Pós-Graduação - fez com que o campo se tornasse mais que um lugar a ser estudado. Ele se configurou num período de tempo da minha vida pessoal e acadêmica em que fui "atravessado" (LARROSA, 2001) por experiências entre dois mundos, que a cada ida e vinda estariam mais entrelaçadas.

Na tentativa de situar-me na aldeia e me permitir reinventá-la, simbolizá-la e significála a partir dos referenciais teóricos e filosóficos definidores do meu olhar, passei a habitá-la física e cognitivamente. Contudo, inevitavelmente minha aldeia passou a habitar-me e a impregnar todos os espaços que tenho frequentado desde então.

Escrever este texto sobre minha experiência etnográfica é uma tentativa de tornar inteligível para mim (aspirante a etnógrafo) e para meus interlocutores - indígenas ou não nesse momento de reflexão e teorização, tudo que acredito ter vivido e aprendido nesse convívio com o povo Apyãwa, no tempo em que habitei e passei a ser habitado pela Aldeia Tapi'itãwa. Ao mesmo tempo, anunciar ao leitor - no intento de sensibiliza-lo ou avisa-lo sobre o ambiente e os cenários em que se deram minhas produções de significados (LINS, 2012).

Em um dos encontros do Grupo de Estudos e Pesquisa em Etnomatemática (GEPEtno), logo depois de retornar de uma das primeiras incursões à Aldeia Tapi'itãwa, no momento em que relatava sobre alguns aspectos da experiência vivida, discutimos sobre o que se esperaria como resultado de minhas observações. Que tipo de registros eu teria ao final?

Pensando no resultado da pesquisa como uma pintura numa tela, o que estaria retratado nesta tela? Com relação ao povo Apyãwa, ali estaria uma imagem de como eles eram no passado; o que resta de elementos originais de sua cultura nos dias de hoje; ou, que direções prováveis a cultura do povo Apyãwa seguirá na dinâmica cultural do encontro com a sociedade ocidental?

A análise etnográfica e sua descrição são interpretativas. O que ela deve interpretar é “o fluxo do discurso social” (Estou , 2008, p. 15) em suas diferentes formas de narrativas. Essa interpretação consiste em produzir uma estrutura de texto - narrativa do pesquisador minimamente inteligível ao olhar acadêmico, como condição de se tornar aceitável para a academia.

Assim, o texto etnográfico é um discurso produzido pelo etnógrafo, quando este realiza esforços físicos e intelectuais na tarefa de tornar realidades inacessíveis - física e cognitivamente - em realidades razoavelmente inteligíveis, objetivando "o alargamento do universo do discurso humano" (GEERTZ, 2008, p. 10). 
É possível que, como pesquisador, ao imergir em outro mundo, tenha sido tocado enfeitiçado, abduzido, cooptado, ludibriado, embebedado - de tal forma que a realidade desenhada em meu discurso etnográfico seja considerada não mais que resultados de delírios, sem nenhuma relação com o que se espera de uma pesquisa científica.

Contudo, estou convencido de que a relevância de um trabalho de pesquisa em Etnomatemática - principalmente pelo seu cunho predominantemente antropológico - está mais no ineditismo dos possíveis cenários de reflexão/diálogo criados, e menos na contemplação distanciada (mesmo estando lá) do exótico.

É justamente com essa espécie de material produzido por um trabalho de campo
quase obsessivo de peneiramento, a longo prazo, principalmente (embora não
exclusivamente) qualitativo, altamente participante e realizado em contextos
confinados, que os megaconceitos com os quais se aflige a ciência social
contemporânea - legitimamente, modernização, integração, conflito, carisma,
estrutura... significado - podem adquirir toda a espécie de atualidade sensível que
possibilita pensar não apenas realista e concretamente sobre eles, mas, o que é mais
importante, criativa e imaginativamente com eles. (GEERTZ, 2008, p. 10).

Nessa perspectiva, entendo que interpretar os discursos sociais em suas diferentes narrativas pressupõe ser afetado pela experiência com a realidade na qual esses discursos são produzidos. Mas, também, compreender o que eles dizem para além do que seja imediatamente acessível aos meus sentidos. É ler e ouvir aquilo que não está sendo direcionado a mim enquanto interlocutor exclusivo (apesar de a minha presença impor, de certa forma, que algo me seja explicado). Inclusive, compreender que a minha presença, provavelmente, criou outras realidades e outros discursos sociais.

Enfim, ter o entendimento de que, apesar de a produção de significados ser minha, não tenho controle algum quanto às direções ou caminhos que ela poderá assumir com meus possíveis (atuais e futuros) interlocutores.

Os diferentes fluxos dos discursos sociais, analisados na perspectiva proposta por Lins (2012), são enunciações produzidas na direção de um interlocutor cognitivo. Ao interpretá-los e produzir meu discurso etnográfico estou assumindo o lugar desse interlocutor que, por sua vez, fala na direção de um interlocutor (também cognitivo), o qual poderá ser da academia ou da aldeia.

Tradicionalmente, a etnografia tem sido o que se pode comparar com a experiência de uma viagem realizada com um pacote turístico, composto por trilhas, cenários exuberantes e convívio com a rotina de populações de diferentes costumes, onde efetuamos intermináveis registros fotográficos e de onde juntamos histórias para contar. Entretanto, ao finalizar a jornada etnográfica, é nos posicionando como acadêmico entre acadêmicos, que faz com que 
nosso texto seja lido, publicado, criticado, citado e ensinado (GEERTZ, 2009), enfim, legitimado.

Por mais que os antropólogos busquem seus objetos de investigação além dos muros da academia [...], eles escrevem seus relatos tendo a seu redor o mundo dos atris, das bibliotecas, dos quadros-negros e dos seminários. É esse o mundo que produz os antropólogos, que os habilita a fazerem o tipo de trabalho que fazem, e dentro do qual o tipo de trabalho que executam tem de encontrar seu lugar, para ser considerado digno de atenção. (GEERTZ, 2009, p. 169).

Ao pretender produzir um texto que seja lido, discutido, criticado e - ao menos em parte - legitimado pelos dois tipos de leitores, o faço depois de passar a habitar e ser habitado por dois mundos. As viagens de idas e vindas, entre aldeia e universidade, não foram percorridas solitariamente por mim.

Populações inteiras de indígenas e não indígenas acompanhavam-me - em questionamentos, histórias, expectativas, saudades, descobertas - e faziam com que cada partida e cada chegada se tornassem apenas a continuidade de um único mundo coabitado por todos que consegui envolver na minha pesquisa.

Assim, é com os sujeitos que, a partir das minhas justificações, foram trazidos para habitar esse novo mundo (constituído e constituinte dos dois antigos) que espero legitimar minhas descrições e o caminho percorrido pelas teorizações produzidas.

Desse modo, acredito que ao retratar essa experiência em um texto escrito, submetendo e - de certa forma - reduzindo minhas descrições sobre o complexo e dinâmico fluxo do discurso social Apyãwa aos limites lineares e gramaticais de um trabalho acadêmico, deverei ter a coragem de apresentar, honestamente, as ideias que consegui produzir.

É necessário que eu tenha, também, tranquilidade para dizer ao povo Apyãwa - e aos pares da academia - meu entendimento sobre as realidades vividas e não o que eu imagino que esperam que eu diga - tanto na academia quanto na aldeia - sobre os resultados conseguidos ao final desse processo.

\section{Considerações finais}

Estou certo de que os resultados do meu esforço intelectual para descrever e produzir teorizações iniciais sobre a experiência junto ao povo Apyãwa nos fornecerão elementos suficientes para refletir, propor eventuais ajustes, rever equívocos e apontar possíveis direções a serem consideradas numa pesquisa em Etnomatemática com povos culturalmente distintos.

A transição entre a etapa de pesquisa de campo e a de produção do texto não é realizada sem sofrimento. A realidade etnográfica não é linear ou plana. O fluxo do discurso 
social nos atravessa, vindo de todas as direções, a qualquer momento; em velocidades, texturas e densidades alternadas e com diferentes aparências e, em quase todo o momento, fala em uma língua desconhecida (Apyãwa).

Os períodos de distanciamento (geográfico) do campo e convívio com os interlocutores do meu universo cultural (família, GEPEtno, colegas de moradia em Rio Claro, ...) serviram como catarses, sem as quais provavelmente me perderia num limbo entre os dois mundos. Entretanto, verdadeira catarse foi necessária para que, ao finalizar o período dedicado exclusivamente ao campo, eu iniciasse o período da escrita do texto acadêmico.

A realidade etnográfica também é múltipla. E, no momento em que nos dedicamos à escrita, essa multiplicidade de caminhos possíveis de discorrer o texto, competindo pelos espaços nas reflexões, não nos permitem escrever as primeiras palavras do primeiro parágrafo. Nesse contexto, necessitei de um tempo para que, aos poucos, esse conflito fosse apaziguado e obtivesse a lucidez mínima que me permitisse definir a abordagem e o estilo discursivo argumentativo do texto.

Acredito serem escolhas que todo pesquisador se obriga a fazer ao reduzir a experiência etnográfica a um texto escrito, que ambiciona ser acadêmico. Faz parte do desafio apontado por Geertz (2009), quando o antropólogo se coloca como autor.

Apesar de não ser antropólogo, muito menos possuir alguma formação acadêmica complementar na área das ciências sociais (a não ser a minha experiência larossiana e profissional de atuar como docente de professores indígenas), decidi praticar etnografia com os Apyãwa. Assim, tomo como minhas as questões levantadas por Geertz (2009) sobre o cenário da escrita etnográfica e o significado de estar lá antes de escrever e ser lido aqui.

Nesse sentido, acredito que a relevância do meu texto não está em apresentar um exótico e inédito mundo dos tempos de Malinowski (1984), cujas informações e detalhes da vida do povo estudado seriam inquestionáveis (mesmo porque, certamente, ele não consideraria meu trabalho como etnográfico).

Há um grande acervo bibliográfico, resultados de pesquisas publicadas sobre os Tapirapé (Apyãwa). Cito dois importantes da antropologia (BALDUS, 1970 e WAGLEY, 1988), uma tese de doutorado na área de linguística (PAULA, 2012), além de uma diversidade de artigos e monografias produzidas pelos próprios universitários Apyãwa, em diferentes áreas do conhecimento, o que nos mostra uma realidade na qual esse grupo seja constituído de pesquisadores e críticos das pesquisas publicadas sobre seu povo.

Em todo o caso, eu estive lá em vários períodos, durante o intervalo de 14 meses, conforme previ no projeto de pesquisa (as imagens fotográficas, em última instância poderão 
testemunhar). $\mathrm{O}$ meu texto trata de minha leitura do que eu acredito ter vivenciado nesse intervalo de tempo no campo.

Como a aldeia atualmente é um lugar acessível, o texto não tem a função de provar que a experiência existiu, mas, sim, chamar a atenção para o fato de que, a partir dessa experiência, seja possível acrescentar novos questionamentos à nossa (dos mayra) visão de sociedade, de ambiente e de conhecimento. Mostrar que o povo Apyãwa é contemporâneo e sua visão de mundo coexiste com a nossa. Assim como sua ciência, suas crenças e seus direitos fundamentais de seres humanos.

Minhas escolhas como pesquisador, ao imergir no universo da pesquisa, foram feitas com base em alguns pressupostos ou premissas, definidores da tese (proposição) que defendo.

A tese (enquanto proposição) está fundada no entendimento de cultura como uma teia simbólica, tecida continuamente a partir da relação entre o ethos e a visão de mundo de um povo que, ao tecê-la, estabelece vínculos, prende-se - que produz, socializa e atualiza seu conhecimento - enquanto discurso social, resultado e resultante dessa prática cultural - e que, cuja análise suscita uma pesquisa etnográfica - enquanto modo de descrever e interpretar o fluxo do discurso social produzido por essa cultura.

A opção por situar-me no campo - enquanto abordagem metodológica - e o meu entendimento sobre como deveria ser essa abordagem, configuram-se numa construção inaugurada no momento da primeira imersão na realidade da aldeia. Implicou na adoção do estilo de inserção e interação com a comunidade, que (acredito) resultou num processo em que as experiências vividas e o tipo de relacionamento estabelecido entre o povo Apyãwa e eu intensificaram-se concomitante e paulatinamente.

Compreender como necessária a construção desse entendimento sobre a pesquisa não foi um processo espontâneo e seguro. A Metáfora da câmera do meu olhar retrata isso. Abrir mão de manipular a câmera simbolizou o momento em que as questões do meu projeto de pesquisa foram abandonadas enquanto norteadoras das minhas ações.

Fazer etnografia junto ao povo Apyãwa oportunizou-me vivenciar uma teia cultural sendo tecida. Possibilitou-me participar de um período histórico do conhecimento sendo produzido, atualizado e ensinado como parte intrínseca à sua prática cultural e ouvir narrativas que explicam e justificam essa prática.

Representou a possibilidade de perceber a teia cultural, não como uma sequência de nós e desenhos repetitivos - uniformes, insípidos, monocromáticos, inodoros e inflexíveis mas, como uma pintura corpórea, uma peça ritualística tecida no próprio corpo, um colar com 
miçangas coloridas, um cocar, uma máscara cerimonial ou uma rede de dormir tecida pelas mulheres Apyãwa.

Tudo sendo produzido com fios, penas, madeiras e outra infinidade de materiais, que assumem, a cada momento, diferentes texturas, colorações, temperaturas, cheiros e sabores do murici, do pequi, da mangaba, da carne da caça sendo moqueada, do peixe assado nos terreiros das casas, da farinha de puba torrada no forno, da cobertura de palha dos telhados.

Enfim, foi a possibilidade de contemplar, em toda essa complexidade, as nuances da personalidade, do jeito de interagir com o outro e com o meio em que se vive, que constituem o povo Apyãwa e que o distingue enquanto grupo cultural.

Praticar etnografia consiste, também, em assumirmos nossa ignorância, mesmo diante das coisas do mundo ao qual pertencemos, e termos capacidade de estranhar. O estranhamento diante do outro é o desconhecimento de nós mesmos. É o que nos mobiliza na construção de novos olhares para realidades já contempladas, com a mesma acuidade dedicada àquelas que contemplamos pela primeira vez, na produção de novos significados.

A ampliação do universo do discurso humano acontece a partir do estabelecimento de um diálogo simétrico entre diferentes mundos, em um ambiente no qual os interlocutores se percebem como iguais nas diferenças. Onde as diferenças são concebidas como principal elemento mobilizador do encontro.

\section{Referências}

BALDUS, Herbert. Tapirapé: tribo tupi no Brasil Central. São Paulo - Edusp; Companhia Editora Nacional, 1970. 512 p.

D’AMBRÓSIO, U. Etnomatemática: arte ou técnica de explicar ou conhecer. $4^{\mathrm{a}}$ Edição. São Paulo: Ática, 1990.

D'AMBROSIO, Ubiratan. Etnomatemática: elo entre as tradições e a modernidade. Belo Horizonte MG: Autêntica, 2002.

D’AMBROSIO, Ubiratan. Sociedade, cultura, matemática e seu ensino. São Paulo - Educação e Pesquisa. v. 31, n. 1, p. 99-120, jan./abr. 2005.

GEERTZ, Clifford. A Interpretação das Culturas. $1^{\text {a }}$ ed., reimpr. Rio de Janeiro - LTC, 2008.

GEERTZ, Clifford. Obras e Vidas: o antropólogo como autor. $3^{\text {a }}$ ed. Rio de Janeiro - Editora UFRJ, 2009.

LARROSA, Jorge. Notas sobre a experiência e o saber da experiência. Campinas, SP - FUMEC. Leituras SME - ${ }^{\circ} 4$ jul. 2001. 
LINS, Romulo Campos. O Modelo dos Campos Semânticos: estabelecimentos e notas de teorizações. In: ANGELO, Claudia Laus [et al.] (orgs.). Modelo dos Campos Semânticos e Educação

Matemática: 20 anos de história. São Paulo - Midiograf, 2012, p. 11-30.

MALINOWSKI, Bronislaw. Argonautas do Pacífico Ocidental. São Paulo - Editora Abril, 1984.

PAULA, Eunice Dias de. Eventos de fala entre os Apyãwa (Tapirapé) na perspectiva da Etnossintaxe: singularidades em textos orais e escritos. 2012, 268 p. Tese (Doutorado em Letras e Linguística) Faculdade de Letras e Linguística, Universidade Federal de Goiás, Goiânia, 2012.

SEVERINO-FILHO, João. Marcadores de Tempos Indígenas: a solidariedade entre os povos e o ambiente que habitam. 2015, 157 p. Tese (Doutorado em Educação Matemática) - Instituto de Geociências e Ciências Exatas, Universidade Estadual Paulista, Rio Claro-SP, 2015.

SEVERINO-FILHO, João. Sobre os marcadores de tempo indígenas: não há vão entre o céu e a terra. In: XI ENCONTRO NACIONAL DE EDUCAÇÃO MATEMÁTICA. XI, 2013, Curitiba. Anais... Sociedade Brasileira de Educação Matemática, 2013, v. XI, p. 01-12.

SILVA, Adailton Alves da. Os Artefatos e Mentefatos nos ritos e cerimônias do danhono: por dentro do octógono sociocultural A’uwẽ/Xavante. 2013, 348 p. Tese (Doutorado em Educação Matemática) - Instituto de Geociências e Ciências Exatas, Universidade Estadual Paulista, Rio ClaroSP, 2013.

WAGLEY, Carlos. Lágrimas de Boas Vindas: os índios Tapirapé do Brasil Central. Belo Horizonte MG: Editora Itatiaia, 1988.

Submetido em Abril de 2015. Aprovado em Agosto de 2015. 